\title{
Monoamine oxidase A is highly expressed by the human corpus luteum of pregnancy
}

\author{
Yumi Takao ${ }^{1}$, Hiroshi Fujiwara ${ }^{1}$, Shinya Yoshioka ${ }^{1}$, Shingo Fujii ${ }^{1}$ and Masamichi Ueda ${ }^{2}$ \\ ${ }^{1}$ Department of Gynecology and Obstetrics, Faculty of Medicine and ${ }^{2}$ Institute for Virus Research, Kyoto University, \\ Sakyo-Ku, Kyoto 606, Japan \\ Correspondence should be addressed to M Ueda; Email: mueda@virus.kyoto-u.ac.jp
}

\begin{abstract}
To investigate the physiological characteristics of the corpus luteum (CL) of pregnancy, we raised a mAb, human corpus luteum (HCL)-4, against human luteal cells obtained from $\mathrm{CL}$ of pregnancy. The affinity-purified antigen from human $\mathrm{CL}$ of pregnancy or placenta using HCL-4 was a $61 \mathrm{kDa}$ protein. The partial amino acid sequence of the antigenic protein was identical to that of human monoamine oxidase A (MAOA, EC1.4.3.4). MAOA has been shown to catabolize catecholamines that were reported to regulate luteal function in $\mathrm{CL}$ and vasoconstriction in various organs. Immunohistochemistry using HCL-4 mAb showed that MAOA was intensely expressed on large luteal cells and moderately expressed on small luteal cells in the $\mathrm{CL}$ of pregnancy. In the CL of menstrual cycle, MAOA was weakly detected on large luteal cells but not detected at all on small luteal cells. Western blotting analysis confirmed the high expression of MAOA in CL of pregnancy. Northern blot analysis also showed the expression of MAOA mRNA in human $\mathrm{CL}$, and showed that its expression was higher in $C L$ of pregnancy than in $C L$ of menstrual cycle. The increased expression of MAOA in the CL of pregnancy suggests the contribution of MAOA to the function of the CL of pregnancy.
\end{abstract}

Reproduction (2008) 136 367-375

\section{Introduction}

During normal pregnancy, the corpus luteum $(\mathrm{CL})$ of pregnancy is formed from CL of menstrual cycle when the embryo implants in the uterus. In the human $\mathrm{CL}$ of pregnancy, luteal cells become hypertrophic and produce abundant steroid hormone until at least 7-9 weeks of gestation to maintain embryo implantation (Adams \& Hertig 1969, Csapo et al. 1973, Yen 1991). Thus, the CL of pregnancy is an essential organ in early pregnancy, and its biochemical and/or functional analyses are important to understand the precise mechanisms of human reproduction.

We previously reported that the expression profiles of several cell surface molecules on luteal cells became changed from $\mathrm{CL}$ of menstrual cycle to $\mathrm{CL}$ of pregnancy. For example, membrane-bound aminopeptidase-N and dipeptidyl peptidase-IV were highly expressed on small luteal cells in the CL of menstrual cycle, but it was hardly detected on small luteal cells in the CL of pregnancy (Fujiwara et al. 1992a, 1992b). Other membrane-bound peptidases, carboxypeptidase-M and endothelin-converting enzyme1 , expressed their isotypes only in $\mathrm{CL}$ of pregnancy (Yoshioka et al. 1998a, 1998b), suggesting that these peptidases are involved in the function of CL of pregnancy (Fujiwara 2004). On the other hand, integrin $\alpha 6$ was expressed on large luteal cells in the CL of menstrual cycle, but it was not expressed on those in the $\mathrm{CL}$ of pregnancy
(Honda et al. 1995). In addition to these cell surface molecules, relaxin gene expression was reported to increase in the $\mathrm{CL}$ of pregnancy (Bogic et al. 1995). Furthermore, we observed that the responses to immune cells in the luteal cell cultures were different between women in mid-luteal phase and early pregnancy. In the luteal cell culture derived from CL of pregnancy, interleukin 4 (IL4) and IL10 productions by the immune cell stimulation were significantly higher than those in the culture derived from $\mathrm{CL}$ collected during the mid-luteal phase. In addition, IL4 and IL10 promoted progesterone production by luteal cells as much as human chorionic gonadotropin (HCG) in vitro (Hashii et al. 1998). These results supported that human $\mathrm{CL}$ of pregnancy is functionally different from $\mathrm{CL}$ in mid-luteal phase and proposed that the $\mathrm{CL}$ function is regulated not only by HCG (Takao et al. 1997) but also by immune cells (Fujiwara 2006).

From these findings, it is speculated that $\mathrm{CL}$ of pregnancy is in a further differentiated stage compared as $C L$ of menstrual cycle. However, there has been no definite evidence to conform this concept. Therefore, in this study, to identify the key substances that are specifically involved in the physiology of $\mathrm{CL}$ of pregnancy, we raised mAbs against human $C L$ of pregnancy and obtained a $\mathrm{mAb}$, named human corpus luteum (HCL)-4, which highly reacted with cytoplasmic molecules in luteal cells in the $\mathrm{CL}$ of pregnancy. 
The subsequent analysis of purified antigen demonstrated that HCL-4 mAb detects monoamine oxidase A (MAOA, EC1.4.3.4). Since MAOA catabolizes biogenic amines such as dopamine, norepinephrine, and epinephrine that are well known to regulate vasoconstriction, this enzyme can be one of the crucial molecules to regulate the function of $\mathrm{CL}$ of pregnancy. Therefore, we further examined the precise expression profiles of MAOA in human follicles, $C L$ of menstrual cycle, and $\mathrm{CL}$ of pregnancy in relation to their differentiation stages.

\section{Results}

\section{The expression profiles of $\mathrm{HCL}-4$ antigen in human follicles and $C L$}

One hybridoma was selected by immunohistochemistry. This $\mathrm{mAb}$ was named $\mathrm{HCL}-4$ and belonged to the $\operatorname{lgG} 3$ isotype.

In growing follicles, 4-5 $\mathrm{mm}$ in diameter, $\mathrm{HCL}-4$ antigen was rarely detected on granulosa or theca interna cells (Fig. 1A-C). In two of three preovulatory follicles, $18-20 \mathrm{~mm}$ in diameter, HCL-4 antigen was weakly detected on theca interna cells but not on the granulosa cells. In the remaining one preovulatory follicle, HCL-4 antigen was not detected on the granulosa cells or theca interna cells (data not shown).
In $\mathrm{CL}$ of the early luteal phase, $\mathrm{HCL}-4$ antigen was weakly detected in the luteinizing granulosa/large luteal cells in three out of seven CL. In the residual four CL, HCL-4 antigen was not expressed on luteinizing granulosa/large luteal cells. In CL of the mid-luteal phase, large luteal cells weakly expressed HCL-4 antigen in three out of six CL (Fig. 1D-F), but not in the residual $3 \mathrm{CL}$. In CL of the late luteal phase, large luteal cells weakly expressed HCL-4 antigen in two out of three CL examined, but not in the third $\mathrm{CL}$. In all menstrual $\mathrm{CL}$, there was no HCL-4 antigen detected on luteinizing theca interna/small luteal cells.

In $\mathrm{CL}$ of pregnancy at $6-15$ weeks of gestation, $\mathrm{HCL}-4$ antigen was highly expressed on large luteal cells and weakly or moderately expressed on small luteal cells (Fig. 1G-l). It was not expressed in ovarian stromal cells or blood vessels.

The intensity score of HCL-4 antigen expression on large luteal cells in $\mathrm{CL}$ of pregnancy was significantly higher than that of $\mathrm{CL}$ of menstrual cycle $(P<0.01)$. $\mathrm{HCL}-4$ antigen expression on small luteal cells in $\mathrm{CL}$ of pregnancy was also significantly higher than that of $\mathrm{CL}$ of menstrual cycle $(P<0.01$; Table 1$)$.

\section{Purification of HCL-4 antigen from a CL of pregnancy}

The antigenic molecule was affinity purified from a CL of the menstrual cycle (CL day 9) and a $\mathrm{CL}$ of pregnancy at 10 weeks of gestation. SDS-PAGE profile showed that
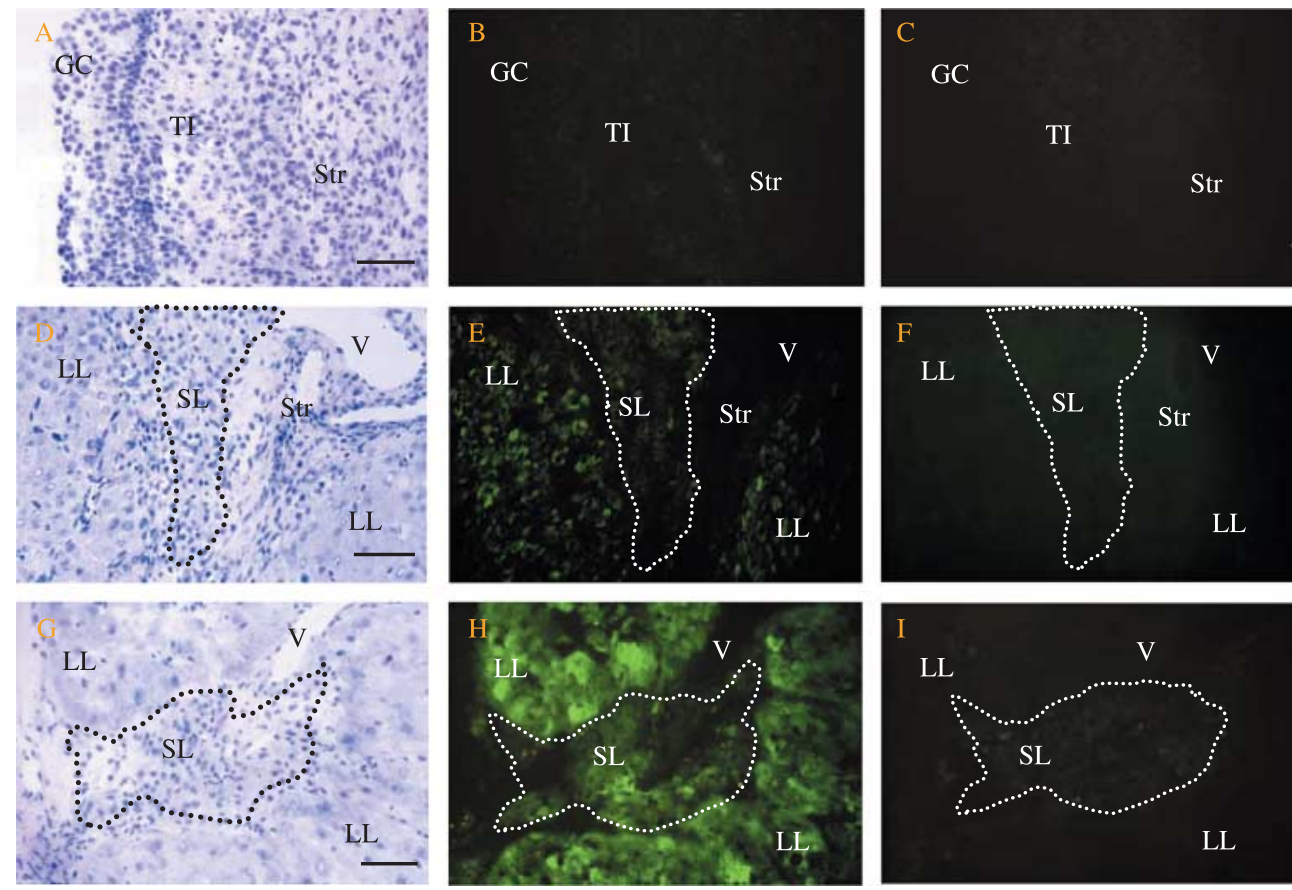

Figure $1 \mathrm{HCL}-4$ antigen expression detected by indirect immunofluorescence staining. (A-C) A growing follicle (5 mm in diameter); (D-F) a CL on day 8; (G-I) a CL at 10 weeks of gestation. (A, D and $G$ ) Hematoxylin and eosin staining; $(B, E$ and $H$ ) staining with HCL-4 mAb; (C, F and I) negative control stained with anti-TNP mAb. (A-C) HCL-4 antigen was not detected on granulosa cells (GC) or theca interna cells (TI). (D-F) HCL-4 antigen was weakly expressed on large luteal cells (LL) and not expressed on small luteal cells (SL). (G-l) HCL-4 antigen was intensely expressed on the cytoplasmic region of large luteal cells and moderately expressed on small luteal cells. Dotted lines show small luteal cell area. V, vessels; Str, stroma cells. Bar shows $100 \mu \mathrm{m}$. 
Table $1 \mathrm{HCL}-4$ antigen expression in human follicles and corpus luteum (CL) detected by indirect immunohistochemistry.

\begin{tabular}{|c|c|c|}
\hline & GC/LL & $\mathrm{TI} / \mathrm{SL}$ \\
\hline Growing follicles (4-5 mm, $n=3$ ) & - & - \\
\hline Preovulatory follicles $(18-20 \mathrm{~mm}, n=3)$ & - & \pm \\
\hline CL of menstrual cycle & & \\
\hline Early luteal phase $(n=7)$ & $\pm^{a}$ & $-{ }^{c}$ \\
\hline Mid-luteal phase $(n=6)$ & $\pm^{a}$ & $-{ }^{c}$ \\
\hline Late luteal phase $(n=3)$ & $\pm^{a}$ & $-{ }^{c}$ \\
\hline$C L$ of pregnancy $(n=11)$ & $\bar{t}++^{b}$ & $++1+^{d}$ \\
\hline
\end{tabular}

GC, granulosa cells; $\mathrm{TI}$, theca interna cells; LL, large luteal cells; $\mathrm{SL}$, small luteal cells; +++ , intensely positive (score 3 ); ++ , moderately positive (score 2 ); + , weakly positive (score 1 ); - , negative (score 0$) ; \pm$, some samples were weakly positive and the others were negative. The expression intensity of $\mathrm{HCL}-4$ antigen on $\mathrm{LL}$ in $\mathrm{CL}$ of pregnancy was significantly higher than that of $\mathrm{CL}$ of menstrual cycle (b versus a; $P<0.01$ ). HCL-4 antigen expression on $\mathrm{SL}$ in $\mathrm{CL}$ of pregnancy was also significantly higher than that of $\mathrm{CL}$ of menstrual cycle (d versus c; $P<0.01$ ).

HCL-4 antigen was a single protein band of molecular mass of $61 \mathrm{kDa}$ (Fig. 2). The staining of $61 \mathrm{kDa}$ protein from $\mathrm{CL}$ of pregnancy was much higher than that from $\mathrm{CL}$ of menstrual cycle.

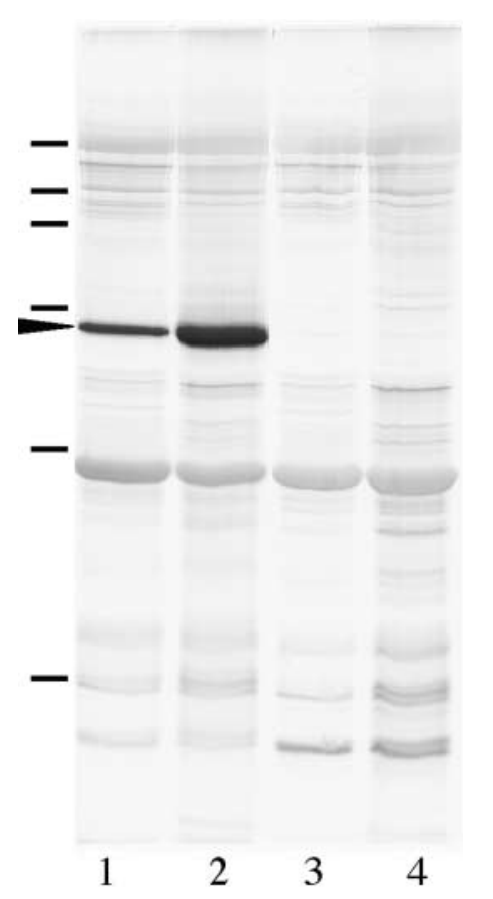

Figure 2 Silver-stained 10\% SDS-PAGE profile of HCL-4 antigen purified from a $\mathrm{CL}$ on day 9 and a CL at 10 weeks of gestation. Lane 1, purified proteins from a CL on day 9 using HCL-4 mAb by immunoaffinity chromatography. Lane 2 , purified proteins from a $\mathrm{CL}$ at 10 weeks of gestation using HCL-4 mAb by immunoaffinity chromatography. Lane 3, purified proteins from a CL on day 9 using anti-TNP mAb (negative control). Lane 4, purified proteins from a CL at 10 weeks of gestation using anti-TNP mAb (negative control). A specific protein band was observed at $61 \mathrm{kDa}$ (arrow head). The amount of the $61 \mathrm{kDa}$ protein from $\mathrm{CL}$ of pregnancy was much higher than that from CL of menstrual cycle. Bars show molecular mass markers of 200, 116, $97,66.2,45$, and $31 \mathrm{kDa}$ from the top to bottom.

\section{The expression profiles of $\mathrm{HCL}-4$ antigen in various human tissues}

HCL-4 antigen was highly expressed in syncytiotrophoblasts of human chorion and placenta (Fig. 3A). It was also expressed in hepatocytes of the human liver. The antigen was hardly detected in mononuclear cells in peripheral blood (data not shown).

\section{Purification of HCL-4 antigen from placenta and partial amino acid sequencing of the protein}

The antigenic molecule was affinity purified from placenta. SDS-PAGE profile showed that the antigenic molecule exhibited the same molecular mass of $61 \mathrm{kDa}$ as that from $\mathrm{CL}$ (Fig. 3C). N-terminal amino acid sequencing of this antigenic molecule was not performed successfully. SDS-PAGE profile of the purified molecule treated with lysyl endopeptidase showed a main protein fragment in the range of molecular mass of $12 \mathrm{kDa}$. The sequence of 20 amino acids from the $\mathrm{N}$-terminus of this protein fragment was identical to
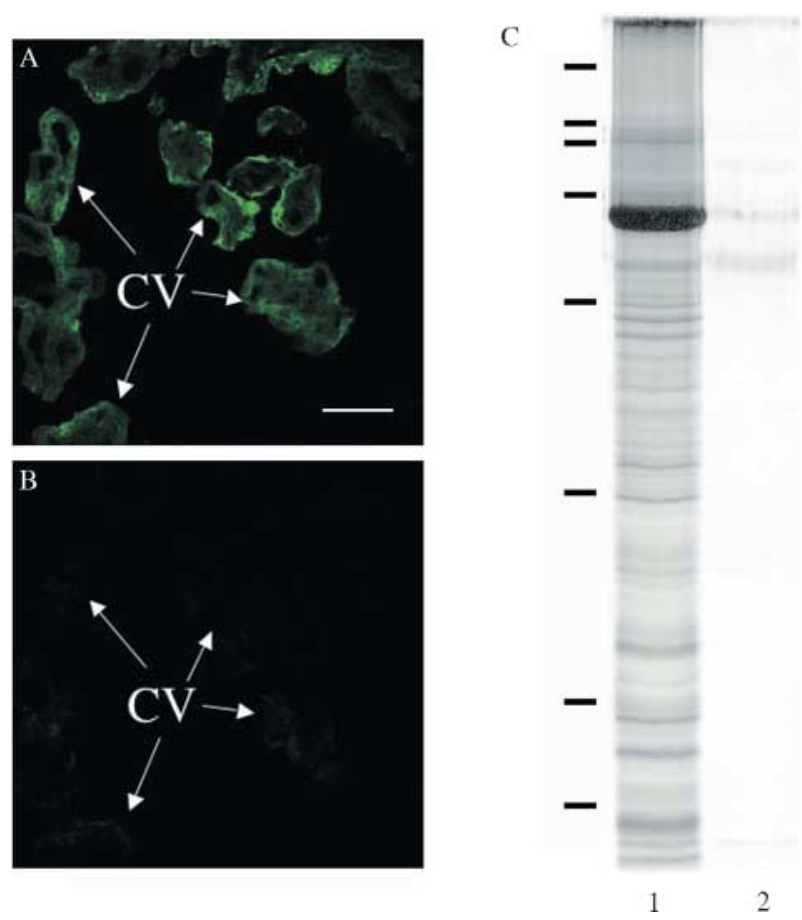

Figure $3 \mathrm{HCL}-4$ expression in term placenta and silver-stained $12 \%$ SDS-PAGE profile of HCL-4 antigen purified from term placenta. (A and B) Sequential frozen sections of placenta at 38 weeks of gestation derived from normal delivery. (A) HCL-4 was expressed on syncytiotrophoblast of chorionic villi (CV). (B) Negative control stained by antiTNP mAb. Bar shows $100 \mu \mathrm{m}$. (C) Silver staining of HCL-4 antigen purified from term placenta. Lane 1, purified proteins from a term placenta using HCL-4 mAb by immunoaffinity chromatography. Lane 2, purified proteins from a term placenta using anti-TNP mAb (negative control). A specific protein band was observed at $61 \mathrm{kDa}$ (arrow head). Bars show molecular mass markers of 200, 116, 97, 66.2, 45, 31, 21.5, and14.4 kDa from the top to bottom. 
that from the 31st amino acid to the 50th amino acid of human MAOA. It also showed $70 \%$ homology with the sequence from the 22 nd to the 41 st amino acid of MAOB (Fig. 4).

\section{Western blotting analysis of MAOA in human $C L$ and term placenta}

Proteins from $\mathrm{CL}$ of the mid-luteal phase (CL on day 8 ) or of pregnancy (7 weeks of gestation) were electrophoresed, and MAOA was visualized with rabbit-specific antibody. Specific protein bands were detected in both $\mathrm{CL}$ of menstrual cycle and pregnancy, which accorded with MAOA protein bands in the placenta (Fig. 5A). The MAOA expression was significantly higher in $\mathrm{CL}$ of pregnancy $(7,7$, and 12 weeks of gestation), compared with that of mid-luteal phases (CL on days 7, 8, and 9, $P<0.01$; Fig. $5 B$ and $C$ ).

\section{MAOA and von Willebrand factor expressions in a CL of pregnancy}

HCL-1 antigen was specifically expressed on large luteal cells, while it was not detected on $3 \beta$-hydroxysteroid dehydrogenase (HSD3B)-positive small luteal cells (Fig. 6B). MAOA was expressed on both HSD3Bpositive large and small luteal cells (Fig. 6C). On the other hand, there was no MAOA expression detected on large or small vessels, which were positively stained by anti-human von Willebrand factor polyclonal antibody (pAb; Fig. 6D).

\section{The expression of MAOA $m R N A$ in human $C L$}

Both the $4.4 \mathrm{kbp}$ main bands and $2.1 \mathrm{kbp}$ weak bands of MAOA mRNA were detected by northern blotting of mRNA respectively isolated from corpus lutea of the mid-luteal phase and pregnancy (Fig. 7A). The MAOA mRNA expression was significantly increased in $C L$ of pregnancy, compared with that of mid-luteal phases $(P<0.05)$, in accord with the immunohistochemical results described above (Fig. $7 \mathrm{~B}$ ).

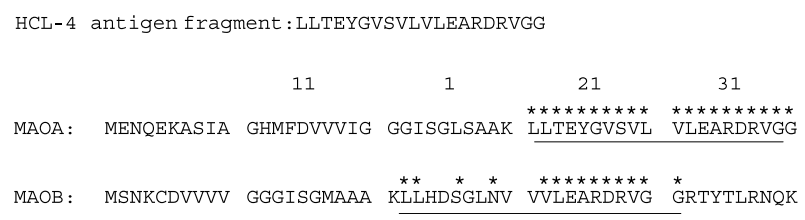

Figure 4 Partial amino acid sequences of the $12 \mathrm{kDa}$ protein fragment derived from HCL-4 antigen, MAOA and MAOB. The sequence of 20 amino acids from $\mathrm{N}$-terminus of $12 \mathrm{kDa}$ protein fragment was identical to that from the 31 st amino acid to the 50th amino acid of human MAOA and showed $70 \%$ homology with the sequence from the 22 nd to the 41 st amino acid of MAOB (Bach et al. 1988). *Amino acid residues that were identical with the HCL-4 antigen fragment.
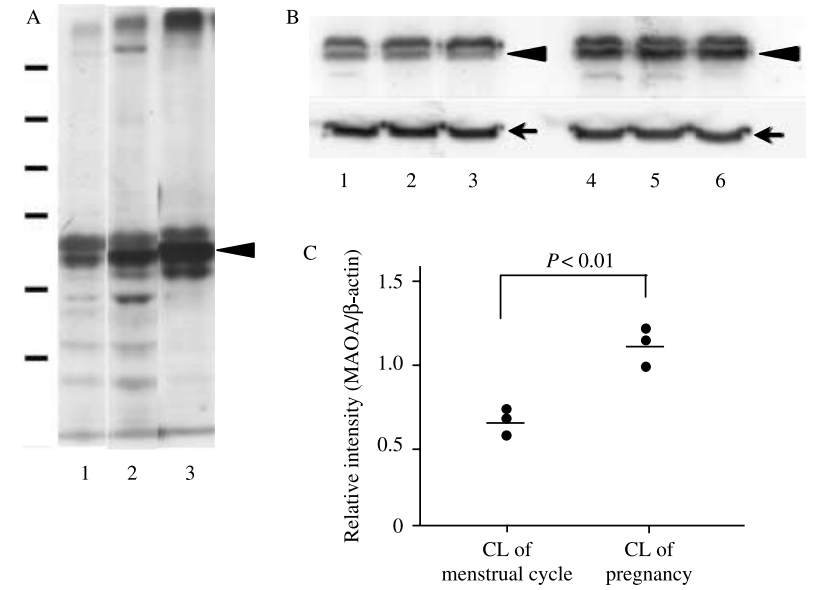

Figure 5 Western blotting analysis of MAOA in human corpora lutea. (A) Proteins from $\mathrm{CL}$ of mid-luteal phase (CL on day 8; lane 1) or of pregnancy (CL of 7 weeks of gestation; lane 2), and from chorion of term placenta (lane 3) were electrophoresed and blotted on PVDF membrane. MAOA was stained with rabbit-specific antibody. Arrowhead represents MAOA, and bars show gel top and molecular mass markers of 250, 150, 100, 75, 50, and $37 \mathrm{kDa}$ from the top to bottom. The staining of MAOA was clearly observed in CL of day 8 and early pregnancy (lanes 1 and 2). (B) Proteins from $\mathrm{CL}$ of mid-luteal phase (CL on days 7, 8, and 9; lanes 1-3) or of pregnancy (CL of 7, 7, and 12 weeks of gestation; lanes 4-6) were electrophoresed and stained with antiMAO (arrowheads) and anti- $\beta$-actin (arrows) pAbs. (C) Relative intensity (MAOA/ $\beta$-actin) in Fig. 5B was significantly higher in proteins derived from $\mathrm{CL}$ of pregnancy than those from $\mathrm{CL}$ of mid-luteal phase $(P<0.01)$.

\section{Discussion}

MAO (EC1.4.3.4) is the membrane-bound enzyme that catabolizes a variety of biogenic amines and is widely distributed in the central nervous system (Berry etal. 1994). MAO includes two types of isozyme, MAOA metabolizing mainly serotonin or norepinephrine and MAOB metabolizing mainly tyramine. The calculated molecular weights of MAOA and -B are 59700 and 58800 respectively and both the enzymes share a $70 \%$ homology of amino acid sequences (Bach et al. 1988). MAOA was reported to be expressed mainly in catecholaminergic neurons in the brain and other tissues including the placenta, liver, and skin. MAOB, on the other hand, was reportedly expressed mainly in serotonergic and histaminergic neurons in the brain, liver, skin, lymphocytes, and placenta (Berry et al. 1994, Auda et al. 1998, Shih et al. 1999, Rodriguez et al. 2001). Recently, it has been suggested that MAOs may play a role in inducing cancers (Agostinelli et al. 2004, Toninello et al. 2006).

In the present study, we raised $\mathrm{mAb}$ that highly reacted with cytoplasmic molecules in the luteal cells in $\mathrm{CL}$ of pregnancy. This $\mathrm{mAb}$ also reacted with syncytiotrophoblasts of placenta. The purified molecule from $\mathrm{CL}$ and placenta showed a molecular mass of $61 \mathrm{kDa}$, which corresponded to the calculated value for MAO (Bach et al. 1988) and accorded with that of MAOA (61 kDa) in adipose tissue (Pizzinat et al. 1999). The partial amino 

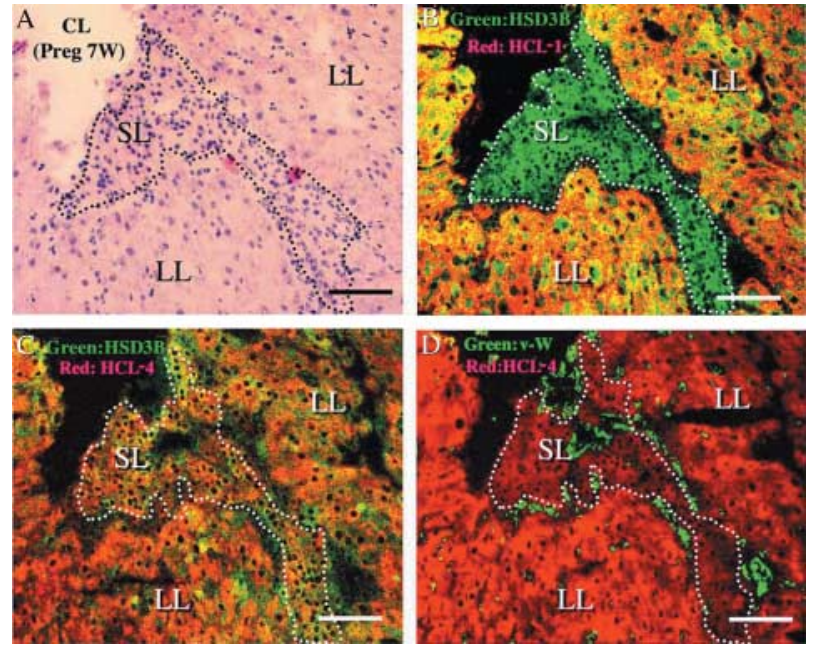

Figure $6 \mathrm{HCL}-4$ antigen and von Willebrand factor expressions in a $\mathrm{CL}$ of pregnancy (7 weeks of gestation) detected by double staining. Sequential frozen sections were stained by (A) $\mathrm{H}-\mathrm{E}$ attaining, (B) redstained by rhodamine using HCL-1 and (C and D) HCL-4 mAbs, (B and C) and green-stained by FITC using anti-HSD3B, and (D) anti-von Willebrand factor pAbs. (B) HCL-1 antigen was specifically expressed on large luteal cells (LL), while it was not detected on HSD3B-positive small luteal cells (SL). (C) MAOA was expressed on both HSD3B-positive large and small luteal cells. (D) There was no MAOA expression detected on large or small vessels, which were positively stained with anti-human von Willebrand factor pAb. Bar shows $100 \mu \mathrm{m}$. Dotted lines show small luteal cell area.

acid sequence of purified antigenic molecule from human placenta was completely identical to the sequence from the 31 st to the 50th amino acid of MAOA. Although it also showed $70 \%$ homology with the sequence of $\mathrm{MAOB}$, from the fact that HCL-4 mAb was not reactive to peripheral blood mononuclear cells or ovarian blood vessels that were reported to strongly express MAOB (Yoshimoto et al. 1986, Berry et al. 1994), it has been concluded that the HCL-4 mAb is specifically reactive to human MAOA.

Immunohistochemical study showed that immunoreactive MAOA protein was abundantly expressed in the $\mathrm{CL}$ of pregnancy. The expression of MAOA on the large luteal cells in $\mathrm{CL}$ of menstrual cycle remained constantly low throughout the luteal phase. MAOA expression on the small luteal cells during menstrual cycle was not detected although weak expression was observed in the theca interna cells in the preovulatory follicles. The apparent difference in MAOA protein expression between $\mathrm{CL}$ of menstrual cycle and pregnancy was also shown by immunoaffinity chromatography (Fig. 2). In addition, western and northern blot analyses showed high expression of MAOA protein at $61 \mathrm{kDa}$ and mRNA at 4.4 and $2.1 \mathrm{kbp}$ in $\mathrm{CL}$ of pregnancy (Figs 5 and 7). These profiles of MAOA mRNA accord with the reported ones that were derived from the adipose tissue (Pizzinat et al. 1999). Taken together with the profiles obtained by immunohistochemistry and SDS-PAGE, we conclude

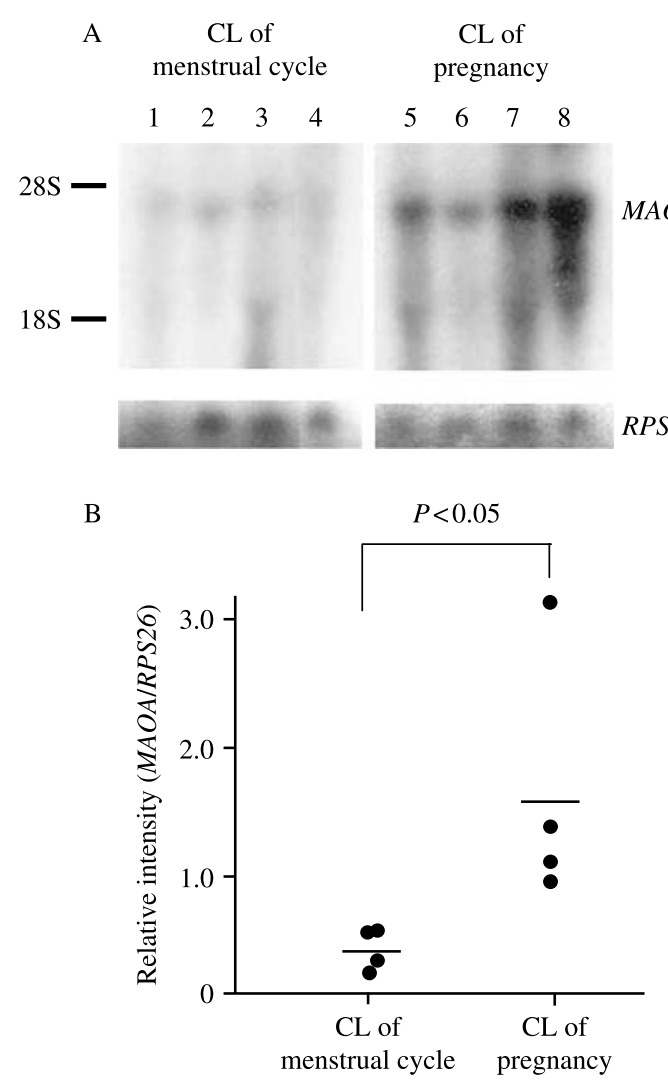

Figure 7 Northern blotting analysis of MAOA mRNA in human corpora lutea. (A) mRNAs from menstrual corpora lutea (on $\mathrm{CL}$ days $7,8,8$, and 9; lanes 1-4) and pregnant corpora lutea (at 7, 7, 9, and 12 weeks of gestation; lanes 5-8) were subjected to northern blotting analysis using probes for MAOA (upper panel) and ribosomal protein S26 (lower panel). The $4.4 \mathrm{kbp}$ main bands and $2.1 \mathrm{kbp}$ weak bands of MAOA mRNA were detected in the mRNAs isolated from both $\mathrm{CL}$ of mid-luteal phases and pregnancy. (B) The level of MAOA mRNA was determined by densitometric scanning of the autoradiograph from the northern blot analysis for $8 \mathrm{CL}$ (lane 1, CL of mid-luteal phase, $n=4$; lane 2, CL of pregnancy, $n=4$ ). The MAOA mRNA level was corrected with RPS26 mRNA expression. The MAOA mRNA expression of $\mathrm{CL}$ of pregnancy was significantly higher than that of $\mathrm{CL}$ of mid-luteal phase $(P<0.05)$.

that MAOA expression increases in $\mathrm{CL}$ of pregnancy, supporting the concept that $\mathrm{CL}$ of pregnancy is in the further differentiated state from $\mathrm{CL}$ of menstrual cycle. However, it should be noted that because these $\mathrm{CL}$ samples were obtained from patients having uterine myoma and benign ovarian cysts, these diseases may anatomically influence vascular circulation and ovarian function affecting MAOA expressions. In northern blot analysis, MAOA mRNA expression in the $\mathrm{CL}$ derived from 12 weeks of gestation, when luteo-placental shift has already occurred (Schindler 2005), was relatively high. Although the precise reasons are unclear, there is discrepancy between the expression intensity among western (Fig. 5) and northern blot analyses. This may be caused by unknown regulatory mechanisms for inherent expression of MAOA. 
In the rat ovary, MAOA-like enzyme activity was detected in the $\mathrm{CL}$ of estrous cycle (Yoshimoto et al. 1986). The total MAO activity in the rat ovary was reported to gradually increase during pregnancy until delivery (Kono et al. 1994). It is widely known that MAO plays a protective role in various tissues by oxidizing amines in circulation. MAOA expressed in the syncytiotrophoblast layer in human placenta was suggested to protect against hypertension caused by catecholamines and serotonin in circulating blood, which arise in toxemia of pregnancy (Yoshimoto et al. 1986). Consequently, high expression of MAOA on the luteal cells of $C L$ of pregnancy suggests that MAOA is involved in metabolizing biogenic amines within $\mathrm{CL}$ of pregnancy. By transvaginal color velocity imaging and pulsed Doppler ultrasonography, human CL blood flow was reported to remain constant during normal early pregnancy from 6 to 12 weeks of gestation (Salim et al. 1994, Alcazar et al. 1996). The vascular network in CL is established in the mid-luteal phase and further matured during early pregnancy. Innervation of peripheral nerve system, which contains a catecholamine system, may develop around newly constructed vessels. In perfused human ovaries, $\boldsymbol{\alpha}$-adrenergic agonists were shown to cause vasoconstriction, while $\beta$-adrenergic agonists cause vasodilation (Varga et al. 1979). Thus, MAOA expressed in the human CL of pregnancy is speculated to regulate luteal blood flow in early pregnancy by decreasing the biological activity of catecholamines.

Accumulating evidence has shown that catecholamines directly affect luteal cell function. Norepinephrine stimulation was reported to enhance progesterone secretion from bovine CL (Bogacki \& Kotwica 1999). The presence of norepinephrine and dopamine was also demonstrated in bovine CL (Battista et al. 1989, Kotwica et al. 1996). Epinephrine was shown to promote progesterone and oxytocin concentration in goat $\mathrm{CL}$ as well (Cooke \& Payne 1998). However, in the rabbit, catecholamines reduced the responsiveness of LH in the luteal cells (Jena \& Abramowitz 1989). It was also reported that the administration of $\beta$-adrenergic receptor antagonist to pseudo-pregnant rabbit did not affect progesterone secretion (Gadsby et al. 1985). The direct effects of catecholamines on primate luteal cell function are controversial. It is assumed that the local concentrations and effects of catecholamines on $\mathrm{CL}$ must be taken into considerations. It was reported that epinephrine and norepinephrine stimulated progesterone production by cultured luteinizing human granulosa cells, which correspond to luteal cells in the early luteal phase (Webley et al. 1988). Although the precise mechanisms for direct effects of catecholamines on luteal cells are unknown, the high expression of MAOA in human $C L$ of pregnancy suggests the physiological roles of catecholamines and MAOA in the function of $\mathrm{CL}$ of pregnancy.
In conclusion, this study indicated that MAOA was prominently expressed on large and small luteal cells in $\mathrm{CL}$ of pregnancy. The apparent increase in MAOA expression in $\mathrm{CL}$ from menstrual cycle to early pregnancy suggests that catecholamines play important roles in the function of $\mathrm{CL}$ of pregnancy.

\section{Materials and Methods}

\section{Samples}

Ovarian tissues were obtained from 30 women, aged between 28 and 43 years old. They had undergone unilateral ovarian cystectomy or oophorectomy and contralateral wedge resection to treat benign ovarian tumors. All women had a history of regular menstrual cycles (28-30 days) and their ovulatory basal body temperature charts showed normal luteal phase length. Macroscopically and microscopically, normal regions of these tissues were used for this study. The following follicles and $\mathrm{CL}$ were studied: three antral follicles that were growing follicles measuring $4-5 \mathrm{~mm}$ in diameter, three preovulatory follicles (18-20 mm in diameter), seven CL from CL day 2 (the day after ovulation) to day 5 , six CL on days $6-10$, and three $C L$ on days 11-14. CL of pregnancy was obtained from 11 pregnant patients aged from 35 to 41 years old. Partial resection of $\mathrm{CL}$ of pregnancy was performed in ten pregnant women who underwent hysterectomy at $6(n=1), 7(n=2), 8(n=1)$, $9(n=2), 10 \quad(n=2), 12(n=1)$, and $14 \quad(n=1)$ weeks of gestation due to uterine myoma $(n=8)$ and/or uterine cervical carcinoma in situ ( $n=2,7$, and 9 weeks of gestation). One pregnant woman at 15 weeks of gestation underwent unilateral oophorectomy due to a huge mature cystic teratoma and a $\mathrm{CL}$ of pregnancy was obtained from the removed ovary. In all patients, fetal growth was normal on ultrasonographic examination. The $\mathrm{CL}$ day was re-evaluated according to the histological dating, using hematoxylin- and eosin-stained tissue sections from $10 \%(\mathrm{v} / \mathrm{v})$ formalin-fixed and paraffinembedded samples (Corner 1956). Human term placentae $(n=5)$ were obtained from normal deliveries and human liver sample $(n=2)$ was obtained from patients undergoing lobectomy for hepatoma. Peripheral blood mononuclear cells were also collected from volunteers as described previously (Kosaka et al. 2002). The use of these tissue samples was approved by the Ethics Committee of Kyoto University Hospital. The informed consent for use of these tissue samples was obtained from all the patients prior to the study according to the rule of Ethics Committee of Kyoto University Hospital.

\section{mAb production}

Luteal cells were isolated from $\mathrm{CL}$ tissue at 15 weeks of gestation as described previously (Fujiwara et al. 1996). Briefly, the $C L$ was separated from the connective tissue, minced with scissors, and then incubated in RPMI 1640 medium (Flow Laboratories, Irvine, Scotland) containing $0.2 \%$ collagenase type I (Sigma Chemical Co.) and 0.01\% DNase I (Sigma Chemical Co.) at $37^{\circ} \mathrm{C}$ for $15 \mathrm{~min}$. The cell suspension was incubated with $1000 \mathrm{IU} / \mathrm{ml}$ dispase (Godo Shusei Co. Ltd, Tokyo, Japan) in RPMI 1640 containing 10\% fetal calf serum 
(Flow Laboratories, McLean, VA, USA) at $37^{\circ} \mathrm{C}$ for $30 \mathrm{~min}$. Eight-week-old BALB/c mice were injected intraperitoneally with $3 \times 10^{6}$ human luteal cells three times with about 1 -month interval. Under ethanol anesthesia, blood was taken from the immunized mice and then the spleen was removed after killing by cervical vertebrae dislocation. Spleen cells were isolated and fused with X63Ag8.653 myeloma cells using polyethylene glycol 15003 days after the last immunization (Köhler \& Milstein 1975). Supernatants from the growing hybridomas were screened by indirect immunofluorescence staining of $\mathrm{CL}$ cryosections, which were prepared as described (Fujiwara et al. 1996). Briefly, fresh CL of menstrual cycle (CL on day 7) or $C L$ of pregnancy (15 weeks of gestation) was embedded in OCT compound (Tissue-Tec; Miles Scientific, Naperville, IL, USA), snap-frozen in liquid nitrogen, and stored at $-80^{\circ} \mathrm{C}$. Frozen tissues were cut into $7 \mu \mathrm{m}$ thick sections using a cryostatic microtome (Histostat, Reichert-Jung, Heidelberg, Germany). The sections were immediately and thoroughly air-dried on Neoplene (Nisshin EM Co. Ltd, Tokyo, Japan)-coated glass slides and then fixed with acetone at $-20^{\circ} \mathrm{C}$. For screening, cryosections prepared from $\mathrm{CL}$ of pregnancy were incubated with supernatants of the growing hybridomas for $60 \mathrm{~min}$ at room temperature. After washing in PBS, specimens were incubated with FITC-conjugated rabbit anti-mouse $\mathrm{pAb}$ (diluted 1:50; DAKO Japan Co. Ltd, Kyoto, Japan) for $30 \mathrm{~min}$ at room temperature in the dark. The slides were washed, mounted with an anti-fade mounting agent (Perma Fluor Aqueous Mounting Medium; Immunon, Pittsburgh, PA, USA) to reduce fluorescence fading, and examined under a fluorescence microscope (Nikon, Tokyo, Japan).

The hybrid cells of interest were cloned twice by limiting the dilution method. The immunoglobulin isotype was determined using an isotyping kit for mouse mAbs (Serotec Ltd, Oxford, UK). The positive hybrid cells were injected intraperitoneally into mice previously treated with pristane $(2,6,10,14$-tetramethylpentadecane; Aldrich Chemical Co., Milwaukee, WI, USA). The IgG3 fraction was purified from ascitic fluid using Affi-Gel protein A (Bio-Rad Labs).

\section{Immunohistochemical examination of $\mathrm{HCL}-4$ antigen expression on $C L$ and placenta}

Purified HCL-4 mAb (5 $\mu \mathrm{g} / \mathrm{ml}$, diluted in culture medium) was used for indirect immunofluorescence staining as described above. Anti-trinitrophenyl (TNP) mouse mAb (IgG3 class, $5 \mu \mathrm{g} / \mathrm{ml}$ ), which was an unrelated $\mathrm{mAb}$ raised against TNP, was used as the negative control (Tsujimura et al. 1990). The slides were washed, mounted with an anti-fade agent (Perma Fluor Aqueous Mounting Medium), and were examined within $6 \mathrm{~h}$ under a fluorescent microscope by two individuals. The intensity of antigen expression was graded from - to +++ based on its fluorescence intensity and scored for statistical analysis $(-$, absence of staining, score $0 ;+$, weak staining, score $1 ;++$, medium staining, score 2 ; and +++ , intense staining, score 3). If judgments differed, the lower value was selected. Two samples, a CL on day 8 (Fig. 1D-F) and a CL of pregnancy at 10 weeks of gestation (Fig. 1G-I), the fluorescence intensities of which were scores 1 and 3 respectively were used as the standard visual assessment throughout this study as described previously (Fujiwara et al. 1994).

For double staining, the slides were incubated with $\mathrm{HCL}-1$ $\mathrm{mAb}(5 \mu \mathrm{g} / \mathrm{ml})$, which specifically reacted with cell surface of large luteal cells in human CL (Fujiwara et al. 1996), HCL-4 $\mathrm{mAb}(5 \mu \mathrm{g} / \mathrm{ml})$, or negative control mAb $(5 \mu \mathrm{g} / \mathrm{ml})$ for $60 \mathrm{~min}$ at room temperature. After washing in PBS, the slides were incubated with rhodamine-conjugated goat anti-mouse $\mathrm{pAb}$ (diluted 1:40; Santa Cruz Biotechnology, Inc., Santa Cruz, CA, USA) for $30 \mathrm{~min}$ at room temperature in the dark. After washing, FITC-conjugated sheep anti-human von Willebrand factor pAb (100 $\mu \mathrm{g} / \mathrm{ml}$; Binding Site, Birmingham, UK) or FITCconjugated sheep anti-rat IgG (negative control, $100 \mu \mathrm{g} / \mathrm{ml}$; Binding Site) was incubated for $30 \mathrm{~min}$ to detect the endothelial cells. After reacting with rhodamine-conjugated goat anti-mouse pAb, the other slides were incubated with rabbit anti-human HSD pAb (Oxygene, Dallas, TX, USA) or rabbit immunoglobulin (negative control) and then reacted with FITC-conjugated swine anti-rabbit pAb (DAKO, Glostrup, Denmark). After washing, the slides were mounted and examined under a confocal laser scanning microscope (Carl Zeiss, Inc., Jena, Germany).

\section{Purification of the HCL-4 antigen from CL of pregnancy}

Purification of the antigenic proteins was performed as previously reported (Honda et al. 1995). Tissue specimens (CL on day 9 or CL of pregnancy at 10 weeks of gestation, $0.5 \mathrm{~g}$ wet weight each) were homogenized in $5 \mathrm{ml}$ of $40 \mathrm{mM}$ phosphate buffer $(\mathrm{pH} 7.3)$ containing $150 \mathrm{mM} \mathrm{NaCl}, 5$ mM EDTA, 1\% Nonidet P-40 (Sigma Chemical Co.), 2 mM p-amidinophenylmethane sulfonylfluoride hydrochloride (Wako Pure Chemicals, Osaka, Japan), $10 \mu \mathrm{g} / \mathrm{ml}$ leupeptin (Peptide Institute, Inc., Osaka, Japan), and $10 \mu \mathrm{g} / \mathrm{ml}$ pepstatin (Peptide Institute, Inc.). After centrifugation $(10000 \mathrm{~g}$, $30 \mathrm{~min}$ ), the concentration of Nonidet P-40 was diluted to $0.3 \%$. The supernatant was passed through a column containing $5 \mathrm{ml}$ anti-TNP-conjugated Affi-gel 10 (Bio-Rad Labs; $2 \mathrm{mg} \mathrm{lgG/ml} \mathrm{gel)}$ at $4{ }^{\circ} \mathrm{C}$ to remove nonspecifically bound components. The through-pass fraction was incubated with $0.1 \mathrm{ml} \mathrm{HCL}-4$ conjugated Affi-gel $10(2 \mathrm{mg} \operatorname{lgG} / \mathrm{ml}$ gel $)$ at $4{ }^{\circ} \mathrm{C}$ for $2 \mathrm{~h}$. After washing the gel extensively, the antigen was eluted with $0.5 \mathrm{M}$ $\mathrm{NH}_{4} \mathrm{OH}$ containing $0.1 \%$ Nonidet $\mathrm{P}-40$. The eluate was dried in vacuo at room temperature. The sample was dissolved in lysis buffer with $0.1 \mathrm{M}$ dithiothreitol, and separated by $10 \%$ SDSPAGE. Proteins in the gel were stained with a silver stain kit (Wako Pure Chemicals). The same procedure was repeated three times with distinct samples.

\section{Purification of the HCL-4 antigen from placenta and partial amino acid sequence analysis}

Human placenta (40 g wet weight) were homogenized in $400 \mathrm{ml}$ of $40 \mathrm{mM}$ phosphate buffer ( $\mathrm{pH}$ 7.3) containing $150 \mathrm{mM} \mathrm{NaCl}, 5 \mathrm{mM}$ EDTA, $1 \%$ Nonidet P-40, and $2 \mathrm{mM}$ $p$-amidinophenylmethane sulfonylfluoride hydrochloride. After centrifugation $(10000 \mathrm{~g}, 30 \mathrm{~min})$, the concentration of Nonidet P-40 was reduced by dilution to $0.3 \%$. The supernatant was mixed with $25 \mathrm{ml}$ anti-TNP-conjugated Affi-gel 10. The unbound fraction was incubated with $1 \mathrm{ml}$ 
HCL-4-conjugated Affi-gel $10\left(2 \mathrm{mg} \mathrm{lgG} / \mathrm{ml}\right.$ gel) at $4{ }^{\circ} \mathrm{C}$ overnight. After washing the gel, the antigen was eluted with $0.5 \mathrm{M} \mathrm{NH}_{4} \mathrm{OH}$ containing $0.1 \%$ Nonidet P-40. The eluate was dried in vacuo at room temperature. The sample was separated by $10 \%$ SDS-PAGE, and proteins in the gel were transblotted onto the PVDF membrane (Millipore Corp., Bedford, MA, USA) in Tris/boric acid buffer with $0.05 \%$ SDS and $20 \%$ methanol. The protein on the PVDF membrane was stained with $0.1 \%$ Coomassie Blue R-250 (Nacalai Tesque, Kyoto, Japan) in 50\% methanol and the protein band was used for $\mathrm{N}$-terminal amino acid sequence analysis. Sequencing was performed by TAKARA, Japan. In some experiments, the dried eluate was treated with lysyl endopeptidase $(1 \mathrm{mg} / \mathrm{ml}$, Nacalai Tesque) at $37^{\circ} \mathrm{C}$ in $0.1 \mathrm{M}$ citrate buffer ( $\mathrm{pH}$ 5.0) overnight, and the protein fragments obtained were separated by $15 \%$ SDS-PAGE. They were transblotted onto PVDF membrane as described above, and N-terminal amino acid sequences of main band were analyzed. The SWISS-PROT database was used in the analysis of amino acid sequence homology.

\section{Western blotting analysis of $C L$}

CL of menstrual cycle (CL days 7,8, and 9) and CL of pregnancy of $7(n=2)$ and 12 weeks of gestation was homogenized by sonication with lysis buffer including $2 \mathrm{mM} p$-amidinophenylmethane sulfonylfluoride hydrochloride, and they were centrifuged at $15000 \mathrm{~g}$ for $20 \mathrm{~min}$. Chorion from the term placenta was also dissolved. Each supernatant including $40 \mu \mathrm{g}$ protein was electrophoresed in 10\% SDS-polyacrylamide gel, and transblotted on the PVDF membrane as above in Tris/glycine buffer with $0.03 \%$ SDS and 20\% methanol. The PVDF membrane was treated with Block Ace (Dainihon Pharmaceutics, Osaka, Japan), rabbit pAb against human MAOA (H-70, Santa Cruz Biotechnology, Inc.) and human $\beta$-actin (ab8227; Abcam Co. Tokyo, Japan), and then horseradish peroxidase (HRP)-conjugated goat antibody to rabbit Igs (DAKO Japan; Honda et al. 1995). HRP was visualized with 3,3'-diaminobenzidine tetrahydrochrolide (Dojin, Kumamoto, Japan). The intensity of the bands was quantified and analyzed by an NIH image software program (Image/J, http://rsb.info.nih.gov/ij/). The data were expressed as a ratio of MAOA densitometric intensity divided by the corresponding intensity of $\beta$-actin.

\section{RNA isolation and northern blotting}

Total RNAs from human menstrual CL on CL days 7, $8(n=2)$, and 9 , and pregnant $C L$ at $7(n=2), 9$, and 12 weeks of gestation were isolated using a commercial kit (TRIzol, Invitrogen). Five micrograms of total RNA from the $\mathrm{CL}$ were reverse transcribed with random primers using a commercial kit (First-Strand cDNA Synthesis Kit; Pharmacia, Inc). The resulting cDNA mixtures were subjected to 30 cycles of PCR amplification with oligonucleotide primers designed based on the sequence of human MAOA CDNA (sense primer 5'-AGGAAATAAGGAAGAAGA-3': positions 1170-1189; antisense primer 5'-ACACTGACAAATAAGAT GGA-3': positions 1848-1867, GenBank M68840; Bach et al. 1988), or with human RPS26 primers (sense primer $5^{\prime}$-GGTCCG TGCCTCCAAGATGA-3': positions 8-27; antisense primer 5'-TAAATCGGGGTGGGGGTGTT-3': positions 308-327;
Vincent et al. 1993). After PCR amplification, $10 \mu \mathrm{l}$ of each PCR product was electrophoresed on a $1.5 \%$ agarose gel, and amplified bands were detected by ethidium bromide staining. After cloning, the PCR product and verifying its sequence, the enzymatically digested cDNA insert was purified and used as a probe for subsequent northern blot analysis that was performed as previously reported (Higuchi et al. 1995). In brief, $10 \mu \mathrm{g}$ total RNAs were electrophoresed on a $1.0 \%$ agarose-formaldehyde gel and then transferred to nylon membranes. The membranes were incubated with a prehybridization solution (Rapid Hyb, Amersham-Pharmacia) for $30 \mathrm{~min}$ at $65^{\circ} \mathrm{C}$ and then hybridized with $\left[{ }^{32} \mathrm{P}\right] \mathrm{dCTP}$-labeled MAOA cDNA probes in the same solution for $2 \mathrm{~h}$ at $65^{\circ} \mathrm{C}$. After hybridization, the filters were washed according to the manufacturer's protocol and then subjected to autoradiography. The membranes were stripped and then reprobed with RPS26 cDNA. The intensity of the bands was quantified and analyzed by an NIH image software program (Image/J). The data were expressed as a ratio of $M A O A$ densitometric intensity divided by the corresponding intensity of RPS26.

\section{Statistical analysis}

Data are shown as means \pm s.E.M. The data of bands of MAOA protein (western blot) and mRNA (northern blot) in corpora lutea of mid-luteal phase and pregnancy were analyzed by an unpaired $t$-test. The expression scores of HCL-4 antigen on large and small luteal cells in $\mathrm{CL}$ of menstrual cycle and $\mathrm{CL}$ of pregnancy were analyzed by Mann-Whitney analysis. The above statistical analyses were performed by the personal computer soft StatView J 5.0.

\section{Declaration of interest}

The authors declare that there is no conflict of interest that would prejudice the impartiality of this scientific work.

\section{Funding}

This work was supported in part by Grants-in-Aid for Scientific Research (nos 16390474 and 17591731).

\section{Acknowledgements}

We acknowledge Drs Toshihiro Maeda and Ryohachi Arai in the Department of Anatomy, Shiga University of Medical Science for helpful discussion.

\section{References}

Adams EC \& Hertig AT 1969 Studies on the human corpus luteum. II. Observations on the ultrastructure of luteal cells during pregnancy. Journal of cell Biology 41 716-735.

Agostinelli E, Arancia G, Vedova LD, Belli F, Marra M, Salvi M \& Toninello A 2004 The biological functions of polyamine oxidation products by amine oxidases: perspectives of clinical applications. Amino Acids 27 347-358.

Alcazar JL, Acosta MJ, Laparte C \& Ruiz ML 1996 Assessment of luteal blood flow in normal early pregnancy. Journal of Ultrasound in Medicine 15 53-56. 
Auda GR, Kirk SH, Billett MA \& Billett EE 1998 Localization of monoamine oxidase mRNA in human placenta. Journal of Histochemistry and Cytochemistry 46 1393-1400.

Bach AW, Lan NC, Johnson DL, Abell CW, Bembenek ME, Kwan SW, Seeburg PH \& Shih JC 1988 cDNA cloning of human liver monoamine oxidase $\mathrm{A}$ and $\mathrm{B}$ : molecular basis of differences in enzymatic properties. PNAS 85 4934-4938.

Battista PJ, Rexroad CE, Poff JP \& Condon WA 1989 Support for a physiological role of endogenous catecholeamines in the stimulation of bovine luteal progesterone production. Biology of Reproduction 41 807-812.

Berry MD, Juorio AV \& Paterson IA 1994 The functional role of monoamine oxidases A and B in the mammalian central nervous system. Progress in Neurobiology 42 375-391.

Bogacki M \& Kotwica J 1999 Influence of noradrenaline on progesterone synthesis and post-translational processing of oxytocin synthesis in the bovine corpus luteum. Theriogenology 52 91-102.

Bogic LV, Mandel M \& Bryant-Greenwood GD 1995 Relaxin gene expression in human reproductive tissues by in situ hybridization. Journal of Clinical Endocrinology and Metabolism 80 130-137.

Cooke RG \& Payne JH 1998 Effects of arterial infusions of adrenalin and acetylcholine on luteal secretion of progesterone and oxytocin in goats. Theriogenology 50 249-253.

Corner GW Jr 1956 The histological dating of the human corpus luteum of menstruation. American Journal of Anatomy 98 377-401.

Csapo AI, Pulkkinen MO \& Wiest WG 1973 Effects of luteectomy and progesterone replacement therapy in early pregnant patients. American Journal of Obstetrics and Gynecology 115 759-765.

Fujiwara H, Maeda M, Imai K, Fukuoka M, Yasuda K, Horie K, Takakura K, Taii S \& Mori T 1992a Differential expression of aminopeptidase-N on human ovarian granulosa and theca cells. Journal of Clinical Endocrinology and Metabolism 74 91-95.

Fujiwara H, Maeda M, Imai K, Fukuoka M, Yasuda K, Takakura K \& Mori T $1992 b$ Human luteal cells express dipeptidyl peptidase IV on the cell surface. Journal of Clinical Endocrinology and Metabolism 75 1352-1357.

Fujiwara H 2004 Functional roles of cell surface peptidases in reproductive organs. Reproductive Medicine and Biology 3 165-176.

Fujiwara H 2006 Immune cells contribute to systemic cross-talk between the embryo and mother during early pregnancy in cooperation with the endocrine system. Reproductive Medicine and Biology 5 19-29.

Fujiwara H, Ueda M, Fukuoka M, Yasuda K, Imai K, Takakura K, Kanzaki H, Suginami H, Mori T \& Maeda M 1994 A new monoclonal antibody (POG-1) detects a differentiation antigen of porcine granulosa and thecal cells and indicates heterogeneity of thecal-stromal cells. Endocrinology 134 1132-1138.

Fujiwara H, Ueda M, Hattori N, Mori T \& Maeda M 1996 A differentiation antigen of human large luteal cells in corpora lutea of the menstrual cycle and early pregnancy. Biology of Reproduction 54 1173-1183.

Gadsby JE, Keyes PL, Schwartz TS, Bill CH II \& Lucchesi B 1985 Do catecholamines play a physiologic role in regulating corpus luteum function in the pseudopregnant rabbit? Biology of Reproduction 32 907-915.

Hashii K, Fujiwara H, Yoshioka S, Kataoka N, Yamada S, Hirano T, Mori T, Fujii S \& Maeda M 1998 Peripheral blood mononuclear cells stimulate progesterone production by luteal cells derived from pregnant and nonpregnant women: possible involvement of interleukin-4 and interleukin10 in corpus luteum function and differentiation. Human Reproduction 13 2738-2744.

Higuchi T, Kanzaki H, Nakayama H, Fujimoto M, Hatayama H, Kojima K, Iwai M, Mori T \& Fujita J 1995 Induction of tissue inhibitor of metalloproteinase 3 gene expression during in vitro decidualization of human endometrial stromal cells. Endocrinology $1364973-4981$.

Honda T, Fujiwara H, Ueda M, Maeda M \& Mori T 1995 Integrin a 6 is a differentiation antigen of human granulosa cells. Journal of Clinical Endocrinology and Metabolism 80 2899-2905.

Jena BP \& Abramowitz J 1989 Catecholamine-induced heterologous desensitization of rabbit luteal adenylyl cyclase: loss of luteinizing hormone responsiveness is associated with impaired G-protein function. Endocrinology 124 1942-1948.

Köhler G \& Milstein C 1975 Continuous cultures of fused cells secreting antibody of predefined specificity. Nature 256 495-497.
Kono H, Lin YC, Yamaguchi M, Zuspan FP, O'Shaughnessy RW, Lee AC, Furuhashi N, Yokaichiya T, Takayama K \& Yajima A 1994 Monoamine oxidase activity in rat organs during pregnancy. Tohoku Journal of Experimental Medicine 172 1-8.

Kosaka K, Fujiwara H, Tatsumi K, Yoshioka S, Sato Y, Egawa H, Higuchi T, Nakayama T, Ueda M, Maeda M et al. 2002 Human chorionic gonadotropin (HCG) activates monocytes to produce interleukin-8 via a different pathway from luteinizing hormone/HCG receptor system. Journal of Clinical Endocrinology and Metabolism 87 5199-5208.

Kotwica J, Skarzynski D, Bogacki M \& Jaroszewski J 1996 Role of dopamine in the secretary functions of corpus luteum in cattle. Journal of Physiology and Pharmacology 47 477-486.

Pizzinat N, Marti L, Remaury A, Leger F, Langin D, Lafontan M, Carpene C \& Parini A 1999 High expression of monoamine oxidases in human white adipose tissue: evidence for their involvement in noradrenaline clearance. Biochemical Pharmacology 58 1735-1742.

Rodriguez MJ, Saura J, Billett EE, Finch CC \& Mahy N 2001 Cellular localization of monoamine oxidase $A$ and $B$ in human tissues outside of the central nervous system. Cell Tissue Research 304 215-220.

Salim A, Zalud I, Farmakides G, Schulman H, Kurjak A \& Latin V 1994 Corpus luteum blood flow in normal and abnormal early pregnancy: evaluation with transvaginal color and pulsed Doppler sonography. Journal of Ultrasound in Medicine 13 971-975.

Schindler AE 2005 Endocrinology of pregnancy: consequences for the diagnosis and treatment of pregnancy disorders. Journal of Steroid Biochemistry and Molecular Biology 97 386-388.

Shih JC, Chen K \& Ridd MJ 1999 Monoamine oxidase: from genes to behavior. Annual Review of Neuroscience 22 197-217.

Takao Y, Honda T, Ueda M, Hattori N, Yamada S, Maeda M, Fujiwara H, Mori T \& Wimalasena J 1997 Immunohistochemical localization of the LH/HCG receptor in human ovary: HCG enhances cell surface expression of $\mathrm{LH} / \mathrm{HCG}$ receptor on luteinizing granulosa cells in vitro. Molecular Human Reproduction 3 569-578.

Toninello A, Pietrangeli P, De Marchi U, Salvi M \& Mondovì B 2006 Amine oxidases in apoptosis and cancer. Biochimica et Biophysica Acta 1765 $1-13$.

Tsujimura K, Park YH, Miyama-Inaba M, Meguro T, Ohno T, Ueda M \& Masuda T 1990 Comparative studies on FCR (FCRII, FCRIII, and FCR a) functions of murine B cells. Journal of Immunology 144 4571-4578.

Varga B, Zsolnai B \& Bernard A 1979 Stimulation of the a-and b-adrenergic receptors in human ovarian vasculature in vitro. Gynecologic and Obstetric Investigation 10 81-87.

Vincent S, Marty L \& Fort P 1993 S26 ribosomal protein RNA: an invariant control for gene regulation experiments in eucaryotic cells and tissues. Nucleic Acids Research 211498.

Webley GE, Luck MR \& Hearn JP 1988 Stimulation of progesterone secretion by cultured human granulosa cells with melatonin and catecholamines. Journal of Reproduction and Fertility 84 669-677.

Yen SSC 1991 Endocrine-metabolic adaptations in pregnancy. In Reproductive Endocrinology, 3 edn, pp 936-981. Eds SSC Yen \& RB Jaffe. Philadelphia: Saunders.

Yoshimoto Y, Sakumoto T, Arai R, Miyake A, Kimura H, Aono T, Tanizawa O \& Maeda T 1986 Monoamine oxidase in rat ovary during the estrous cycle. A histochemical study by a new coupled peroxidatic oxidation method. Endocrinology 119 1800-1804.

Yoshioka S, Fujiwara H, Yamada S, Nakayama T, Higuchi T, Inoue T, Mori T \& Maeda M 1998a Membrane-bound carboxypeptidase-M is expressed on human ovarian follicles and corpora lutea of menstrual cycle and early pregnancy. Molecular Human Reproduction 4 709-717.

Yoshioka S, Fujiwara H, Yamada S, Tatsumi K, Nakayama T, Higuchi T, Inoue T, Maeda M \& Fujii S $1998 b$ Endothelin-converting enzyme-1 is expressed on human ovarian follicles and corpora lutea of menstrual cycle and early pregnancy. Journal of Clinical Endocrinology and Metabolism 83 3943-3950.

Received 3 January 2008

First decision 26 February 2008

Revised manuscript received 30 April 2008

Accepted 21 May 2008 